\title{
NSF: a voluntary organisation that cuts both ways
}

\author{
Gary Hogman
}

The National Schizophrenia Fellowship (NSF) was founded in 1972 following a period of correspondence in The Times initiated by John Pringle. It currently has a membership of around 7000 people linked to over 160 groups throughout England, Wales and Northern Ireland. The majority of the members are informal carers. The organisation provides direct care to about $\mathbf{3 0 0 0}$ people each week.

Since $1989 / 90$ the NSF has multiplied its turnover from $£ 1 \mathrm{~m}$ to almost $£ 10 \mathrm{~m}$ in $1993 / 4$, an actual growth of over eight times within four years, averaging a doubling every financial year. Its asset base has also grown from $\$ 680 \mathrm{k}$ to $£ 2.12 \mathrm{~m}$ in the same period, more than three times. NSF employs somewhere in the region of 500 staff throughout England, Northern Ireland and Wales. Most of this growth reflects the development towards a major service delivery organisation for both members and the wider client base of users and carers within local community.

\section{Resources before rhetoric}

NSF has always campaigned for a range of high quality health and social services. An integral part of any combination of such services would include hospital (or hospital 'style' care). NSF's policy of freezing hospital closures is not synonymous with preference for them as an ideal model of care. The philosophy of care in the community is one which we share with the government. However, if the current lack of rehabilitation and acute beds, waiting lists for secure beds, people with schizophrenia in prison and on the streets, people being discharged without adequate aftercare, families forgotten about and left to care with no support, is what the government believes to be community care, then we do not agree.

The current pressure on acute beds, with wards running at over $120 \%$ occupancy rate, waiting lists of 30 to 40 for secure unit places and estimates of 1300 people with schizophrenia in prison and 15000 homeless, means that capital investment is urgently required. Operating with such resource constraints is almost impossible. NSF estimates that an extra $\$ 500$ million (revenue) a year is required for community care for people with a severe mental illness. The message to the government is clear, without more resources this version of community care will fail.

\section{'Cutting both ways'}

The organisation can be said to have two sides: one which provides a positive response to severe mental illness by providing high quality services and involving both users and carers; and another which is more likely to be negative, campaigning about deficiencies in service provision, available resources and policy.

\section{Service provision}

Following local activity in the 1980 s some social services departments and health authorities funded local projects such as drop-in centres for service users which indirectly benefited those people by providing informal support. Projects developed around the country offering a range of provision from befriending schemes to fully registered 24 hour nursing care.

With the onset of community care in 1991, the government made a decision to develop resources within the community for the care of the mentally ill. NSF had the expertise, through our national network of members, to make effective use of these resources. In addition the organisation was able to capitalise on its volunteer staffing and skills.

NSF operates in eight regions throughout England, Northern Ireland and Wales. A range of housing projects exist from semi-supported, through rehabilitation to 24 hour nursing home care. There are information, advice and advocacy services in urban and rural settings as well as sheltered employment projects. Finally, day centre and drop-in services are provided which. as in all of NSF's projects, involve sufferers and carers in their management and future development.

Increasingly NSF is benefiting from the contract culture of the re-organised health service 
delivering individual contracts worth over $£ 800000$. The relocation of responsibility for care to the social services departments, with funds transferred across from the Department of Social Security (DSS), has allowed NSF to act as the provider of accommodation in liaison with local housing authorities.

At NSF's core are the National Advice Service, training department and 'Forresters' respite hotel.

The Advice Service, in conjunction with 160 support groups and 37 trained advocacy-advice workers, provides a range of aid to the public and NSF members alike. Many people need help with basic needs such as welfare benefits and somewhere to live. Ensuring that they receive their full entitlement can be a lengthy process - some benefit forms are up to $\mathbf{4 0}$ pages long. Ensuring that they are correctly filled in is one thing but convincing the adjudicating officer at the DSS that someone with a severe mental illness is entitled to severe disability benefit is quite another (where necessary, representation at tribunals and inquests is often required). Aside from practical issues, information about severe mental illness, treatment and side effects is provided. The Advice Service has close contacts with the NSF Professional Advisory Committee whose members include representatives from the Royal Colleges and other bodies.

Issues that arise through the advice network often become, and certainly inform, the work of the training department. It ran 35 training events last year, covering such topics as the mentally disordered offender, court diversion, suicide, religion and mental illness, motivating sufferers and identifying mental illness. Attenders at conferences can be roughly broken down as follows: $41 \%$ police and prison officers; $16 \%$ health authority personnel; $10 \%$ social services personnel; with the remainder made up of users and carers. NSF is well aware of the important part played by the police in providing community care for people with a severe mental illness and their interest in courses clearly reflects this.

The Forresters hotel in Hampshire started providing respite for families and people suffering from severe mental illness in September last year. The building has 16 rooms and can have 19 residents. It is the first facility of its kind in England and has begun to plug a huge gap that has existed in service provision for many years.

\section{Campaigning and research}

Originally NSF started as a mutual support operation based on the needs of the active membership. They were quick to realise that they could be more effective by publicising their area of interest and campaigning for more resources and a recognition of the role that carers play. Ensuing public debate, both regionally and nationally, developed into the recognition that the health and social services were not effectively meeting these particular needs of their population.

Campaigning through the media and lobbying MPs and Peers became a significant part of the organisation's activity. Issues that have featured in the last few years include the Mental Illness Specific Grant (a ring-fenced, revenue only grant available to local authorities for the provision of social care to people with a severe mental illness). After being credited as the driving force behind its creation NSF produced two independent reports on its progress (Hogman \& Westall, 1991; Hogman, 1992).

Many years of lobbying MPs eventually bore fruit with changes in the Code of Practice for the Mental Health Act 1983 (including the clarification of admission to hospital under the Act "in the interests of the person's health" even if there is no risk to their own or other people's safety). The organisation has also produced research into the use of hospital beds, suicide and schizophrenia and the care programme approach (Hogman, 1991, 1993).

NSF's current campaigning work is anchored by our ten point plan. This calls for a freeze on hospital closure; an extra $\$ 500$ million revenue a year for community care; a guarantee of 52000 high staffed beds; a statutory obligation on the part of health and local authorities to provide the care programme approach; and respite, information and personal services for informal carers. Press activity is mainly reactive, with $90 \%$ of our national coverage being in the broadsheet newspapers and TV/radio news and documentary programmes.

\section{NSF and psychiatrists}

NSF members and staff have maintained a close and beneficial relationship with the Royal College of Psychiatrists and a number of clinicians around the country. The Professional Advisory Committee provides a forum for doctors, representatives from other professions and NSF staff and members to discuss and make recommendations on contemporary problems.

The advice department, perhaps partly due to the nature of its contact with people who experience problems in accessing services, do come across psychiatrists who are less than helpful. They are aware that there are clinicians who see treatment purely in terms of medication and even then do not (or perhaps cannot) prescribe the newer neuroleptics avallable such as clozapine and resperidone. Similarly such doctors are less likely to refer people for innovative therapies such as cognitive-behavioural therapy, when appropriate and requested. 
Some psychiatrists do not ensure that discharge from hospital is carried out in accordance with section 117 of the Mental Health Act, and where it applies, the care programme approach. Many are unaware that a substantial number of suicides closely follow discharge from hospital and that therefore the quality of the discharge arrangements are crucial.

\section{Conclusion}

The transition from a traditional voluntary organisation providing support and information to members (the majority of whom are carers) to a large service provider (about $90 \%$ of staff nationally are now involved directly in service provision) in such a short time has been at once exhilarating and frightening! NSF's Trustees debated long and hard before deciding to provide care directly as opposed to relying on exerting pressure on the government nationally and statutory providers locally. However, now the benefits of being both a campaigner and provider (and possibly in the future a purchaser?) are being realised.

\section{Acknowledgement}

I would like to thank Keith Bell on whose work part of this article was based.

\section{References}

Hogman, G. \& Westall, J. (1991) The Mental Illness Spectic Grant: the early days. NSF.

- (1991) The Future Looks Unstable: a pllot study of hospttal closure and bed avallabllity. NSF.

- (1992) Window Dressing: the Care Programme Approach and the Mental Illness Spectic Grant, April 1991-April 1992. NSF.

- (1993) Suicide and Schizophrenia. NSF.

Gary Hogman, Research and Policy Officer, National Schizophrenia Fellowship, NSF National Office, 28 Castle Street, Kingston upon Thames, Surrey KT1 1SS

For information please contact: Research and campaigning, Gary Hogman 081547 3937; Training, Fred Carney 081547 3937; Advice, Mary Teasdale 081974 6814; Forresters, Jane John 0703843042.

\section{Prevention in Psychiatry}

\section{Edited by Eugene S. Paykel and Rachel Jenkins}

Prevention has made a major contribution to the control of many medical diseases. In psychiatric disorders its place has been problematic. This book seeks a balanced appraisal of the evidence and possibilities, and will be of interest to service planners, trainees and all mental health professionals. The chapters cover a wide range from general principles to approaches to specific disorders, age groups, speciality problems, and settings. The expert evidence gathered in the preparation of the original College policy document is discussed comprehensively, making this book essential reading for anyone concerned with mental health care.

\section{$\bullet £ 12.50 \bullet 215 p p . \bullet 1994 \bullet$ ISBN 0902241729}

Available from the Publications Department, Royal College of Psychiatrists, 17 Belgrave Square, London SW1X 8PG (Tel. 0171-235 2351) 